Enjy Noah Muhammad Hamouda

\title{
Displacement in the Poetry of Etel Adnan and Mohja Kahf
}

\author{
Research by \\ Enjy Noah Muhammad Hamouda \\ Helwan University \\ Faculty of Arts \\ English Department \\ Literature Section
}

Teaching Assistant of English Language at Badr University (BUC) 

Enjy Noah Muhammad Hamouda

\section{Abstract}

Although America is a country that depends upon immigration, it seems to have a highly racist system of ethnic classification. In America, the definition of 'citizenship' depends basically on color, race, and religion of the immigrants. Accordingly, a sense of discrimination, rejection, and humiliation is imposed on the different ethnic minorities in America, including the Arab Americans. By means of theories from "Diaspora" criticism, this research paper traces different experiences of discrimination against the Arab Americans in general through analyzing the poetry of two Arab American female poets, exploring the way in which these poets challenge the troubling oppressed/negative representations of Arab Americans in the United States. In addition, this research paper tries to bring to light the realistic image of the Arab Americans as represented in the poetry of Etel Adnan and Mohja Kahf. Etel Adnan (b. 1925) is a Lebanese female poet, critic, and painter. She represents the sophisticated divided-self of the immigrants in her book of poetry There: In the Light and the Darkness of the Self and of the Other (1997). As a postcolonial 
Enjy Noah Muhammad Hamouda

critic and a poet, she highly emphasizes the idea of displacement and its psychological consequences on her as an Arab American citizen. Secondly, Mohja Kahf (b. 1967) is a Syrian Muslim American poet and novelist, whose book of poetry E-mails from Scheherazade (2003) shows her feeling of being discriminated/downsized regarding being both an Arab and a Muslim.

Keywords: "Diaspora", Displacement, Arab Americans; Dramatic Monologue; Etel Adnan; There: In the Light and the Darkness of the Self and of the Other; Mohja Kahf; E-mails from Scheherazade.

\section{Introduction}

The dilemma of race is a dominant factor in American social history. The dual legacies of slavery and massive immigration deeply affect the ways in which citizens are being viciously classified and discriminated. Regarding the fact that Arab American literature is one of a minority groups in America that migrate from their countries in the Middle East to live in America, this research paper discusses the experience of the Arab Americans' displacement, in relation to racism in the hostland, within the framework of "Diaspora" criticism. "Diaspora" criticism exposes some 
Enjy Noah Muhammad Hamouda

argumentative issues, for example reconsidering the definitions of nation and citizenship and attempting to change the negative fixed ideologies on the marginalized immigrants' race. The immigrants who come from the Middle East, attempt to introduce a full understanding of the diaspora entity's struggles. Notions of what constitutes ethnicity are negotiated in "Diaspora" criticism, which becomes a way of mapping how complexity and difference appear as cultures travels, interacts, and mutates. The Arab American diaspora passes through many challenges which include their history of immigration, racialization in the US, and the development of their own unique literature. Thus, through using the "Diaspora" concept of displacement on the two Arab American poetesses' poetry Etel Adnan (b1925- ) There: In the Light and the Darkness of the Self and of the Other and Mohja Kahf(b1967- ) E-mails from Scheherazad, this research paper analyzes the exploitations and struggles of the Arab Americans.

"Diaspora" is a Twentieth-century theory, which tends to understand and appreciate the crises and burdens carried by the immigrants. This critical theory, "Diaspora", takes the concept of diaspora as its object of investigation, and seeks out a framework to form a solid field, so as to 
Enjy Noah Muhammad Hamouda

discuss the displaced communities in a way that takes every pressure into consideration. "Diaspora" is a theory which emerged in the middle of the Twentieth century, in order to understand the identity crises faced by the immigrants, "Diaspora's main emphasis is on displacement and exile of populations who moved from their home to another home forcibly or voluntarily" (Mishra 27). "Diaspora" is seen as a controversial field, which in a short period of time can expose and analyze successfully many arguments regarding dispersion and migration. Although the diasporists rebuke each other regarding their perception of "Diaspora", they at the end reach mutual truths of the field.

"Diaspora" is being critically appreciated by diasporists, the critics, who are working on Diaspora arguments, through the release of their articles in journals such as Diaporas, Public Sphere, Cultural Anthropology, and etc. Moreover, the significant criticism is to be credited to diasporists, such as Paul Gilroy's The Black Atlantic, Stuart Hall's 'Cultural Identity and Diaspora', James Clifford's 'Diasporas', William Safran's 'Diasporas in Modern Societies: Myth of Homeland and Return', John A Armstrong's 'Mobilized and Proletarian Diasporas', 
Enjy Noah Muhammad Hamouda

American Political Science Review', Robin Cohen's Global Diasporas: An Introduction, Walker Conner's The Impact of Homelands Upon Diasporas', Gabriel Sheffer's Modern Diasporas in International Politics, and James Clifford's "Diasporas".

Every theory seeks out analyzing some problematic issues and concerns, which characterize and distinguish it from other theories. Basically, "Diaspora" theory focuses on: "the experiences of displacement and homelessness, the ideologies of home and nation, the cultures of diaspora, the politics of multiculturalism, the predicament of the minorities, the exilic perspective, the redefinition of cosmopolitanism, identity questions, and issues relating to race"(Miller 1). Thus, "Diaspora" is an immense and rich discipline, which is affected conceptually by the modern world concerns and arguments. Each one of the diasporists is trying to introduce what best distinguishes "Diaspora" theory from other theories. In "Diasporas in Modern Societies: Myths of Homeland and Return", William Safran argues for the importance of the inclusion of six principles that characterize diasporas as follows: 
Enjy Noah Muhammad Hamouda

The concept of diaspora can be applied to expatriate minority communities that are characterized with: 1) they or their ancestors have been dispersed from a specific original center to foreign regions; ... 3) they believe that they are not and perhaps cannot be-fully accepted by their host and therefore feel partly alienated and insulated from it. (83-84)

These characteristics are considered the guidelines that are approved by William Safran, Robin Cohen, John A Armstrong, and others. The critics agree that the main characteristics of "Diaspora" to be revolving around some basic principles. First, the critics intentionally stress the necessity of being dispersed from a homeland and moving to another country, hostland, to settle in, this is due to the fact that the critics want to eliminate other kinds of dispersed populations which are not physically dispersed from the homeland. For example, William Safran, who excludes other dispersed populations from being categorized as diasporas, argues that the "Magyars cannot be considered under Diaspora as they have been expatriated politically not territoriality. Gypsies have no notion of their place of origin" (87). Next, with the shocking negative 
Enjy Noah Muhammad Hamouda

stereotyping of immigrants according to their backgrounds, such as America's fixed negative orientalist ideologies against immigrants from Arab world where Islam is the religion of a majority of people, the immigrants are convinced with the fact that no matter how peaceloving and intelligent citizens they are, they are not fully accepted by the hostland. Consequently, by foregrounding these characteristics, the Arab Americans can be considered and categorized as Arab American diaspora that share much of "Diaspora" characteristics, such as dispersion and not belonging to the hostland.

Accordingly, this research paper tackles Arab Americans within the framework of "Diaspora", as it exposes what kinds of struggles and exploitations the Arab Americans face since arrival at the hostland, such as being perceived as aliens by the host. Hence, this research highlights the main conflicts and problems that are being discussed in the poetry of the two Arab American poetesses, Etel Adnan and Mohja Kahf. With regards to the selected collections of their poetry, the foregrounded struggles and challenges that face the Arab American diaspora are depicted through the main concept of 'displacement' in terms of how racism against the Arab 
Enjy Noah Muhammad Hamouda

American minority leads to the dislocation of the Arab Americans from the American society and treatment of them as outcasts.

In "Diaspora" context, displacement is one of the characteristics of diaspora entity's race with regards to the two territories, the homeland and the hostland. Dispersion and immigration of population have increased since the Nineteenth century. Between being tragically displaced from the homeland and being discriminated in the new place, the hostland, "Diaspora" is the only welcoming terrain for those displaced population. Thus, this research paper discusses displacement through the analysis of the dual relationship among the two main entities: diaspora entity itself (displaced communities) and the hostland's system of racism/ classification (faulty justifications behind degrading as well as rejecting the immigrants especially from the Arab world and the images of the racism embodied on the Arab American diaspora).

It can also be argued that place and space are of basic importance to all the questions of the "Diaspora" criticism and migration studies. Needless to say, the "Diaspora" criticism borrows some concepts from "Post-colonialism", such as 'displacement'. In order to understand how 
Enjy Noah Muhammad Hamouda

the "Diaspora" criticism adds to and modifies these Post-colonial ideas of 'place' and 'displacement' in diasporic context, we have to check the backgrounds of these definitions. Initially speaking, the term 'dislocation', which is used repeatedly as a synonym for 'displacement', is defined in The Key Concepts by Bill Ashcroft as:

Dislocation is a term for both the occasion of displacement and the experiences associated with this event. The phenomenon may be a result of transportation from one country to another by slavery, imprisonment, or a consequence of willing or unwilling movement from a known to an unknown location. It affects all those who, as a result of colonialism, have been placed in a location that, because of colonial hegemonic (the dominance of one state within a confederation) practices, needs, in a sense, to be 'reinvented' in language, in narrative and in myth. A term often used to describe the experience of dislocation is - literally 'unhousedness' or 'not-at-home-ness'... Diasporic communities formed by force or voluntary migration may all be affected by this process of dislocation and regeneration too, and this has certainly 
Enjy Noah Muhammad Hamouda

been argued by some recent critics of the diasporic and migrant experience. (69)

According to Bill Ashcroft, whether this act of displacement, leaving one authentic home to another strange one is voluntary or forcibly, the displaced communities go through living in the 'unhousedness' or 'notat-home-ness' state. Additionally, Ashcroft argues that the displaced/ diasporic communities are exposed to be negatively affected by this process of dislocation in terms of finding no home for belonging. Thus, the diasporists include the necessity of physical dislocation from a homeland moving forward to the hostland, new home, in order to properly analyze the diasporic communities' experience of dispersion.

Since moving to another new land, 'place', is the completion part of the migration movement, it is important to clarify what defines this 'place'. 'Place' is defined by Ashcroft as:

The concept of place itself may be very different in different societies and this can have quite specific political effects in the extent of displacement. The idea of not owning the land but in some sense being 'owned by it' is a way of seeing the world 
Enjy Noah Muhammad Hamouda

that is so different from the materiality and commodification of a colonizing power, that effective protection of one's place is radically disabled when that new system becomes the dominant one... The concepts of place and displacement demonstrate the very complex interaction of language, history and environment in the experience of colonized peoples and the importance of space and location in the process of identity formation. (163)

The idea of 'place' is flexible enough to include any place, whether under Colonization or immigration, that it is hard to identify one's self with, regardless the fact of physical belonging to. In other words, moving to another new 'place', anyone may think of considering this new 'place' as home, yet they do not belong to it. Due to the fact that diasporas are familiarized as people sticking to their beliefs, they are not fully accepted by their hostland, a sense of psychological displacement in the hostland is proceeded. Thus, the relationship between the 'place' the immigrants inhabit and the 'place' they are physically displaced from is important in highlighting the tensions between these two territories, the homeland and the hostland. Similarly, these tensions and conflicts are being displayed 
Enjy Noah Muhammad Hamouda

and depicted in the poetry of the two Arab American poets, Adnan and Kahf.

The ideas of place and 'displacement' impose double tensions on diasporas in terms of living in one place and not belonging to it. Bill Ashcroft refers to the difficulty of identifying this diaspora entity as "the crises of identifying the self and the place" (9). Diaspora entity does not belong to a "place". It is needed to identify the entity of diaspora within its place. In the modern world, there is a need to expose as well as analyze the predicaments laid upon displaced communities, such as dispersion and migration. The experience of displacement and migration is described as: "diaspora is a disadvantaged product of modernized polities" (Armstrong 393). Basically "place" and displacement conflict is defined as the "subjective split between the geo-physical entities of here and there, of homeland and hostland. The home and host entities are seen as cohesive entities. Suspended between two such terrains, there is a straightforward correlation between territorial-nationalistic and psychological-ideological (dis)location” (Mishra 16). 
Enjy Noah Muhammad Hamouda

"Diaspora" criticism seeks out identifying this new being, diaspora/an uprooted entity, in terms of its characteristics, reasons for migration, kinds, and what hardships are expected to face in the hostland. It tackles some of the prominent problems of this new being; Walker Conner describes diaspora as "the segment of people living outside the homeland" (Conner 16). Diaspora criticism has given some synonyms for the entity, where the migrants live, such as the third space, border, hyphen, diaspora space, veritable third, third-time space, and contact zone. First, what characterizes this 'contact zone' is investigated by a variety of diasporists. For instance, Gabriel Sheffer defines clearly the modern diasporic entity as "ethnic minority groups of migrant origins residing and acting in host countries but maintaining strong sentimental and material links with their countries of origins-their homelands" (3). This means that, the diasporic entity includes those collective displaced communities living outside their homeland. Accordingly, any entity could be considered a diaspora only if it belongs to an original homeland. Therefore, Safran excludes from the "Diaspora" criticism any dispersed population which is not physically displaced, such as Magyars. 
Enjy Noah Muhammad Hamouda

Immigrants within the same cultural atmosphere cannot be considered under Diaspora, such as Palestinians. To sum up, Safran stresses the importance of displacement notion, which enforces the immigrants to make some kind of sacrifice, such as giving up speaking their native language. Considering the immigration and displacement as important factors in distinguishing diaspora, the Arab American diaspora suffer from displacement that is caused by racism imposed on their race in the United States. So, this research paper traces racism imposed on the Arab Americans leads to dislocation and not belonging in the poetry of the Adnan and Kahf.

The Arab American diaspora can be analyzed within the framework of "Diaspora" criticism. Owing to the reality that the destruction caused to the homes of the Arab countries that is made by the European colonization, this pushes the Arabs to search for a new home; therefore, they go to America with their Arab American dream, to have a normal and stable life and home for them and for their sons. The term 'Arab Americans' is defined by Michael W. Suleiman as follows: 
Enjy Noah Muhammad Hamouda

The term 'Arab Americans' refers to the immigrants to North America from the Arabic speaking countries of the Middle East and their descendants. There are two major waves of Arab immigration to North America. The first lasted from 1870s to World War II and the second from World War II to the present. According to the U.S. immigration figures, about 130,000 Arabs had immigrated to the U.S by the late 1930s; then 350,000 on the eve of World War II; next in 1990s it is estimated at two and one half to three million.

The Arab Americans originally are those who came from Arab countries in the Middle East. The phrase 'the Arabic-speaking countries' refers to Algeria, Bahrain, Egypt, Iraq, Jordan, Kuwait, Lebanon, Libya, Mauritania, Morocco, Oman, pre-1948 Palestine and Palestinians, Qatar, Saudi Arabia, Sudan, Syria, Tunisia, United Arab Emirates, and Yemen. Somalia and Djibouti are also members of The League of Arab States and have some Arabic-speaking populations. The Arab countries are twenty one, but later on Comoros was added to its union to be twenty two countries that were located in two continents, Africa and Asia (Suleiman). The Arab immigration to U.S. started from the late Nineteenth century to 
Enjy Noah Muhammad Hamouda

the present with an estimation of the number three million immigrants in the late Twentieth century. Thus, the Arab American diaspora is the entity that is squeezed between their original homelands in the Arab countries, Adnan is from Lebanon and Kahf is from Syria, and their hostland in the U.S.

Analytically speaking, there are several causes for dislocating from and leaving the homeland moving to another hostland that determine the kind of diaspora. Diasporas, the third space, has been differently affected by several reasons that were behind the migration and displacement process; it is divided into kinds of diasporas. The reasons for the Arab immigration to America fall into two categories: push and pull factors.

First, the pushing factors for migration, Suleiman argues that the most important reasons for Arab emigration are "economic necessity and personal advancement" (2). The economy of the Arab world countries witness an obvious fluctuation due to civil wars and colonization, while the Arabs were trying to live in a safe, stable, and powerful place. Economically, politically, and socially speaking, the Arab countries witnessed pushing factors for immigration to the U.S. starting from 
Enjy Noah Muhammad Hamouda

1880s as Michael W. Suleiman clarifies:

The economy of Mount Lebanon suffered major crippling blow in the mid-1800s. The first was the opening of the Suez Canal which sidetracked world traffic from Syria to Egypt and made the trip to the Far East so easy, so the Japanese silk became a major competitor for the Lebanese silk industry... Many Lebanese Christians, who constituted most of the early Arab arrivals in the North America, emphasized religious persecution and the lack of political civil freedom as the main causes of their emigration from lands ruled by an oppressive Ottoman regime. Under the Ottoman rule, Christians in the Syrian province were not accorded equal status with their Muslim neighbors. (5)

The pushing factors for leaving the Middle East are various and strong. These pushing factors in the homeland may include: economic fluctuation in some countries' income and the sectorial riots under an oppressive power, the Ottoman regime. Economic difficulties hit some Arab countries, causing difficulty in coping. Moreover, the political corruption and sectorial riots created other problems, such as civil wars in 
Enjy Noah Muhammad Hamouda

Lebanon and instability in Syria. Due to the social and political changes in the Arab countries, there is a need for democracy and the freedom of opinions. All these incidents in the Middle East help much in pushing the Arabs seriously to search for another place where they can live well, express their opinions freely without being victimized, and believe in their different religions freely without being afraid of being discriminated and fought against.

Secondly, the pulling factors for migration related to the hostland. While trying to live in a destructive, developed, and corrupted homeland was a hard task to achieve in the Middle East, there are attractive advanced methods of life in the 'West' that create a persistent desire for the Arabs to search for any hope to live well in other place. These pulling factors are clarified by Suleiman as follows:

In addition to the economic, political, and social causes of the early Arab immigration to North America, some incidental factors should be cited. Among these are improved transportation and communication facilities worldwide, development of steam navigation that made the sea voyage safer and shorter...American 
Enjy Noah Muhammad Hamouda

missionaries' presence in Arab countries ignited a desire especially among the graduates of the American schools and colleges in Arab countries...New immigrants were driven out of their homes as a result of regional conflicts (e.g., Palestinian-Israeli, Arab-Israeli, Iraq-Iran, Iraq-Kuwait) or civil wars (e.g., Lebanon, Yemen) or as a consequence of major social and political changes in the homeland that made life difficult, especially for the wealthy or middle class in Egypt, Iraq, Syria, and other countries. The search for a democratic heaven, where it is possible to live in freedom without political or economic harassment and suppression by the government was a strong motivation. (4-9)

Adding to the reasons for early immigration, the modern fascinating life image propagated by the American missionaries in the Arab countries attracts the Arabs to migrate, such as the fascinating attractive means of transportation in America, the hostland. Thus, an imaginary perception of how life seems in the other side, the West, is much wanted and desired. Thus, the reasons behind the dispersion and immigration characterize the kind of diaspora. 
Enjy Noah Muhammad Hamouda

Considering the reasons for migration, there are several kinds of diasporas. Robin Cohen introduces several kinds of dispersions, such as "victim's diaspora, a labour diaspora, imperial diaspora, trading diasporas, and cultural diasporas" (X). In other words, the reasons behind immigration determine the kind of diaspora. Moreover, living in the hostland, diaspora preserves "their ethnic or ethnic-religious identity" (Sheffer 9). Ethnic diasporas keep some feelings of belonging towards their homeland. Thus, Arab American diaspora is an example for ethnic voluntary/involuntary diaspora, which highly keeps a contact with the homeland when they face harsh stereotyping and fixed negative ideologies against their race in the hostland. Depending on the idea of 'binary opposition', the system of putting two entities in a constant clash where there is a superior and an inferior, the orient / the occident, the self/other, and the homeland/hostland, the Arab Americans oppose the Americans. The Arab Americans are negatively perceived based on their belonging to the 'Orient' the inferior that opposes the 'West' the superior. They face many hardships in the hostland, such as the negative classification, rejection, racism, fixed ideologies of inferiority, and unfair 
Enjy Noah Muhammad Hamouda

registration rules of citizenship.

Displacement is related to the journey leaving the authentic homeland and moving to settle in the hostland. After leaving the corrupted/ colonized homeland and immigrating to the new hostland, immigrants are exposed to a very harsh experience of racism in the hostland that causes their sense of dislocation. Displacement is related to the racist classifications over the Arab Americans in the hostland. Racism in America leads to the Arab Americans' loss of belonging.

How does it feel to be different, unwelcomed, unfairly eliminated, and viciously perceived? The answer to this question is exposed in the hostland, which is powerful enough to practice whatsoever it thinks good for the country's benefit. This harsh experience of stereotyping the immigrants is based on a huge system of negative representations and fixed ideologies towards justifying the acts of humiliation. Walker Conner defines diaspora as "that segment of people living outside the homeland" (16); they seek out establishing a new terrain to settle in. The hostland perceives the immigrants at somehow in a very raciest way. Therefore, the hostland is keen on defining the race of the immigrants 
Enjy Noah Muhammad Hamouda

to its territory. As a result, "Diaspora" criticism has attracted the critics' attention to the hostland in order to provide a clear understanding of this entity's identity. Conner defines the hostland as "the state is a political entity with regulatory powers over a geographical territory" (16). Hence, Walker refers to the hostland as a powerful entity, as it owns a policy and a territory as well. This is proven in treating any new visitor to this powerful territory. Displaced communities have to fit in according to this territory policy. Logically speaking, any country sets its rules, such as perception of its race, citizenship, selfhood, culture, religion and so on.

Tragically speaking, immigrants do not expect that kind of rejection and hostility towards them; they are negatively categorized from the very moment of arrival at the hostland. Racism and discrimination towards the immigrants result in a "troubled relationship with host countries" (Cohen 180). Coming from another place, born with a different race, speaking a different language, or believing in a different religion does not make a human being less than the other.

Therefore, "Diaspora" criticism sheds light on the background of the negative fixed ideologies against the marginalized minorities, the 
Enjy Noah Muhammad Hamouda

opposition between the hostland and the homeland in terms of Orientalism. In "Diaspora" context, the system of creating the binary-opposition way of thinking targets "othering of vast numbers of people, and their construction as inferior, in which a binary and implacable discursive oppositions are crucial not only for creating images of the outsider but equally essential for constructing the insider, the usually white male self" (JanMohamed 61). The ideology of constructing two opposed entities, such as "self"/"other", gives the privileged rank to one over the other, this is done by powerful imperialistic 'self'. Thus, the powerful country, the hostland, manipulates the need to construct some fixed ideologies on the cultural difference to preserve its authentic identity.

Due to the trend of the imperialistic powerful countries, such as America, to construct racial and cultural differences in their systems to maintain dominance over its minorities, "Diaspora" investigates some of the argumentative questions. For example, are human beings essentially the same or different? Additionally, Ania Loomba argues that “is difference primarily defined by racial attributes?" (104). In terms of constructing distinction between races, Loomba disapproves the 
Enjy Noah Muhammad Hamouda

perception of difference as criteria of categorizing races into superior and inferior. This is intentionally done by imperialistic powerful countries to justify any kind of elimination of the 'different' inferior races. In postcolonial theory, the notion of 'binarism', from binary, is defined by the French structural linguist, Ferdinand de Saussure. 'Binarism' is explained as follows:

Holding that signs have meaning not by a simple reference to real objects, but by their oppositions to other signs'. Each sign is itself the function of a binary between the signifier, the 'signal' or sound image of the word, and the signified, the significance of the signal, the concept or mental image that it evokes. Saussure held that although the connection between the signifier and signified is arbitrary, once the link is established, it is fixed for everyone who speaks that language. While signs mean by their difference from other signs, the binary opposition is the most extreme form of difference possible - sun/moon; man/woman; birth/death; black/white. Such oppositions, each of which represents a binary system, are very common in the cultural construction of reality. (Russell 17) 
Enjy Noah Muhammad Hamouda

With referring to the ideology of binary opposition, life can be divided neatly between good or evil, light or dark, white or colored, and love or hate. When we encounter binary opposition, we think of two.

In order to counter the imperialistic misrepresentations of racial construction, it is better to highlight the background behind the word "race". The central issue of the heart of anthropological, cultural, and scientific debates throughout the Nineteenth century is "Are human beings a single species or not?" (Loomba 116). Scientifically speaking the word race is initially being argued in the Nineteenth century whether it is applicable or not to mix between races as mentioned by Robert Young "debates about the theories of race in the Nineteenth century, by settling the possibility and the impossibility of hybridity, focused explicitly on the issue of sexual unions between whites and blacks" (9). It is just a matter of debate whether different races are equally the same or not, but later on it becomes a suggestive fact by science, such as anthropology, that races are not the same. 
Enjy Noah Muhammad Hamouda

From the moment of landing on the new land, the hostland, there is a system of negative unfair fixed ideologies set for the immigrants, which later is the justification for any kind of exploitation done by the government. In terms of the rules for granting the immigrants the citizenship, citizenship is based on the raciest definition of race. The background of the word race is clarified in relation to racism according to Ashcroft in Key Concepts In Post-Colonial Studies as follows:

'Race' is a term for the classification of human beings into physically, biologically and genetically distinct groups. The notion of race assumes, firstly, that humanity is divided into unchanging natural types, recognizable by physical features that are transmitted 'through the blood' and permit distinctions to be made between 'pure' and 'mixed' races. Without the underlying desire for hierarchical categorization implicit in racism, 'race' would not exist. Racism can be defined as: a way of thinking that considers a group's unchangeable physical characteristics to be linked in a direct, causal way to psychological or intellectual characteristics, and which on this basis distinguishes between 
Enjy Noah Muhammad Hamouda

'superior' and 'inferior' racial groups. Physical differences did not always represent an inferiority of culture or even a radical difference in shared human characteristics...But with the rise of European imperialism and the growth of Orientalism in the nineteenth century, the need to establish such a distinction between superior and inferior finds its most 'scientific' confirmation in the dubious analysis and taxonomy of racial characteristics. (199)

Scientifically speaking, the word race defines the classification of human beings according to physical features which are transferred through blood. This distinguishes a pure race that keeps on producing its race without mixing from another. In the same way of thinking, the word race is understood in colonial context, racism, to portray a hierarchical categorization of races into the civilized races and the backward races. The civilized races revolve around the white European model; races such as yellow or black are unfairly appreciated. Scientific racism suggests the assumption that race is responsible for cultural formation and historical development. Nations are regarded as the expression of biological and racial characteristics. Having various species of mankind, there must be a 
Enjy Noah Muhammad Hamouda

natural aristocracy among them, the dominant white species are opposed to the lower races who by their origin are destined to serve the nobility of mankind, and may be tamed, trained, and used like domestic animals, or used for physiological or other experiments. Wherever the lower races prove useless for the service of the white man, they must be abandoned to their savage state.

Thus, the scientific definitions of race starting in the Eighteenth century lead to racial classification of human beings, such as aristocracy and servants. Consequently, thinking of different races as intellectually and psychologically inferior, according to their different physical characteristics, is approved by science at that time as Loomba documents "colour was the most important signifier of cultural and racial difference" (109). This racial difference is highly unfair and very raciest. There is a tendency behind that linking between the physical characteristics and the mentality to viciously dominate and colonize the other, that is done by the rise of the European imperialism as Loomba argues "in fact, in several colonial situations stereotypes provided an ideological justification for different kinds of exploitation" (113). Moreover, there are responding 
Enjy Noah Muhammad Hamouda

cultural systems to accept the notion that the physical differences between races distinguish races into superior and inferior, such as Orientalism. Orientalism is a system of establishing some distinctions between species into superior and inferior. These distinctions, misrepresentations, need to be solved with referring to some unchanging notions of racism or Orientalism that are the criterion for all kinds of manipulations as Ashcroft states "the Orient was a word which later accrued to it a wide field of meanings, associations, and connotations, and that these did not necessarily refer to the real Orient but to the field surrounding the word" (203). Orientalism, which is a Western system of thinking of highly negative fixed ideologies against the Orient, the Middle East, is modified in the modern world to include any kind of unfair stereotyping of people, such as American Orientalism. In colonial and migration contexts, Orientalism plays a great role in manipulating the marginalized peoples' mentalities in a convincing way to dehumanize and maintain dominance over the different races as inferior; this is shown in American Orientalism which is a vicious system of classification of the immigrants in general and the Arab immigrants in specific. 
Enjy Noah Muhammad Hamouda

The negative fixed ideologies towards marginalized peoples, whether under colonization or dispersion, depend mainly on the European Western experience of Orientalism that is adapted to modern world predicaments of dispersion, as American Orientalism. In order to victimize a group of people to maintain power over them, there should be a manipulation of their thinking. There are attempts to convince the victimized peoples due to dispersion that they are inadequate citizens due to their color or religion; therefore, they cannot be fully accepted, relates to Orientalism. Edward Said defines Orientalism as:

A style of thought based upon an ontological and epistemological distinction made between 'the Orient' and 'the Occident'... Orientalism can be analyzed for dealing with the Orient- dealing with it by making statements about it, authorizing view of it, describing it, by teaching it, settling it, ruling over it: in short, Orientalism as a Western style for dominating, restructuring, and having authority over the Orient... The relation between the Occident and Orient is a relationship of power, of domination... The Orient is a specific kind of knowledge about the specific places, 
Enjy Noah Muhammad Hamouda

peoples, and civilizations...The American Orientalism was a kind of intellectual authority over the Orient within Western Culture. $(2,3,19$, and 203)

Orientalism is introduced by the Western colonization over the Middle East. The West convinces himself that he has to civilize the Orient, the place where exotic beings are living in fantasy; he chooses to hold that burden. Whereas, this dehumanization of the other, they are from another race believing in another religion, is due to maintain power over them and execute the economic plans in the Middle East. Consequently, this system of categorizing people unfairly can be applicable to any devalued group of people such as diasporas in America especially the Arab American diaspora, who are viciously rejected for many generations in America. The Arab American loyalty is always questioned. (Said)

American Orientalism is the replacement of Britain and France with America in terms of having power over the world with regards to the fixed ideologies about the marginalized people. America looks at the immigrants who come from the Arab world from a highly negative raciest perspective due to two things: their race, aliens, and their religion 
Enjy Noah Muhammad Hamouda

of Islam, terrorists. Ania Loomba explains the shift of powers to produce American Orientalism as follows:

Anyone resident in the West since 1950s, particularly in the United States, will have lived through an era of extraordinary turbulence in the relations of East and West, no one will have failed to note how 'East' has always signified danger and threat during this period ...Some things have contributed to making the even the simplest perception of the Arabs and Islam into a highly politicized matter: one, the history of popular anti-Arab and anti-Islamic prejudice in the West, which is reflected in the history of Orientalism, the hostile image of Islam as a reflection of his own chosen weakness; two, the struggle between the Arabs and Israeli Zionism and its effects upon American Jews as well as the liberal culture and the population at large. Thus, if the Arab occupies space enough for attention, it is as a negative value. He is seen as the disrupter of the Israeli and the West's existence; three, the Arab is an oil supplier, this is another negative characteristic...The web of racism, cultural stereotypes, political imperialism, dehumanizing ideology holding 
Enjy Noah Muhammad Hamouda

in the Arab or the Muslim is very strong indeed. (24- 26)

Due to the original influence of the old fixed ideas against the Arabs by the European Orientalism, the basics of American Orientalism are borrowed from the European model in terms of the hostility toward the race of 'Arabs' and religion of 'Islam'. This is regarding the reasons behind the highly unfair representations of Arabs. It is a threat on the West, whether by the religion or by the control over the oil. This leads to perceiving the Arab immigrants according to these backgrounds which seem fair enough to cause them all these kinds of elimination, exploitation, and rejection. The American Orientalism is affected by the European model of Orientalism in terms of devaluing the Arabs. They perceive the inhabitant of the 'East' negatively according to their race 'Arab' and religion 'Islam'. So the Arabs do not receive that fair attention, they only get that attention which is a negative one. They are seen as a threat to America and its ally Israel. It is clear that the Arabs are a clear disturber of Israeli existence. This is shown in the wide range of Arab-Israeli wars in the Twentieth century. In addition to that, the Arabs are the oil supplier that supports the West with its needs of oil. 
Enjy Noah Muhammad Hamouda

Thinking of the Arabs as a source of threat to the West, such as America, the western negative representations of the Arabs start to exist in the American theater such as Suleiman mentions "American entertainment in its various forms stereotypes Arabs by casting them into narrowly defined and usually negative images, these negative images insinuate themselves into the American consciousness and that this process inevitably has political consequences" (272). Hostility towards the Arabs is symbolized in the American racism against the Arab Americans. Thinking of the Arab Americans as not Americans but Arabs, leads to stereotyping and humiliating them.

Moreover, the American Orientalism executes Orientalism towards a new entity, its minorities, diasporas who immigrate to U.S. Being negatively stereotyped due to sticking to the authentic self is just a harsh feeling. Diasporas were hyphenated between discrimination and alienation; they are in the "zone of tension" (Mishra 28). Due to prejudice against diasporas, Stuart Hall summarizes diasporas' feeling of how does it feel to belong to nowhere, by stating that "people who have been dispersed forever from their homeland ... belong to no one 
Enjy Noah Muhammad Hamouda

particular home" (36). Physically living in a place but psychologically displaced from it leads to a loss of belonging and alienation. As a result, diasporas try to search for feeling at home again "they continue to relate to that homeland in a way or another" (Cohen 84). So, America the new Occident, sets its system of negative fixed ideologies against its Orient, the Arab Americans. This is shown in the raciest classification towards the Arab American race as, not quite white, which affects all the educational, health care, judicial trials, and religion.

The race of the immigrants to America is a main factor in determining the future of them in America. The American Orientalism uses the binary opposition in preferring some races over others; the preferred race is the white one. The immigrants from Arab countries are being perceived differently as Suleiman clarifies:

The U.S. authority began to claim that Arabs had no right to naturalization and citizenship because they allegedly were Asians and did not belong to the white race...Even during the World War II, the status of the Arab immigrants remained unclear. A Muslim Arab immigrant from Yemen was denied U.S. citizenship 
Enjy Noah Muhammad Hamouda

because Arabs as a class are not white and therefore not eligible for citizenship, especially because of their dark skin and the fact that they are part of the Mohammedan world. An Arabian Muslim was granted citizenship status under the 1940 nationality act... Woman who have come from the most traditional countries of the Arab world have experienced a greater restriction of their freedom in the United States...Arabs in America are often treated as white but not quite. $(8,7$, and 14$)$

Depending on the fixed ideologies held against the Arabs, the immigrants from the Arab world were viciously victimized. For a long period of time the Arab Americans are not granted the right of citizenship due to their color of not being white. Arab women are to expect double kinds of racism against them. Seeing the Arab women in the distorted image of women as submissive and are treated just as sex objects degraded the look to these women. The Arab Americans are considered by every means as inferior and belong to inferior race and religion. This leads to exploitation of the Arab Americans. Not only do they feel being rejected and negatively seen, but also they feel the weakness for not having any 
Enjy Noah Muhammad Hamouda

power to reject, defend, or protect themselves from this harsh stereotyping. The Arab Americans are accurately described by Joanna Kadi in Food for Our Grandmothers as "Arab Americans are the Most Invisible of the Invisibles" (xix). This is the truth that faces the Arab Americans for so long time since immigration.

In addition to that, there are so many examples for the exploitation that are performed against the Arab Americans, such as the political exploitation. Racism in the Court System is shown as follows:

Arabs receive harsher sentences than non-Arabs for similar crimes. Not many Arabs are registered as voters, and their names therefore are not for jury duty. Some of the lawyers stated that many Arabs who are called for jury duty do not want to serve because they could not afford to be away from their jobs... To circumvent a biased jury, some lawyers preferred bench trial, a process by which the case is presented to the judge, who alone decides the case. There are some of judges who refuse to ask for interpreter, stating that their English is very good although it is not...A recent legislation entitled Anti-Terrorism and Effective Death Penalty 
Enjy Noah Muhammad Hamouda

Act signed into law on April 24, 1996... Under the terms of this law, the government has the right to deport an immigrant even if he or she has not committed any crime. (Suleiman 72 and 73)

Racism is shown in the legal injustice in treating the Arab Americans. The legal system reflects the government humiliation and rejection towards the Arab immigrants. In addition to that there is domestic violence performed against the Arab Americans. Legislations which are signed for the sake of humiliating and rejecting the Arab Americans are huge. From the negative information concerning the Arabs, wife abuse is seen as an acceptable Arab behavior and custom; therefore, the police ignore the complaints of any abused Arab American woman. Another way of domestic violence is the police attitude to overreact as mentions "If the police find any bruises on the wife or the children, the whole family is placed in a shelter to protect them from the abusing father and husband, and the reply to the husband, you are not back home now; you are in America" (Suleiman 75). Ignoring or overreacting in any problem concerning the Arab Americans is deliberately executed. Thus, American Orientalism is seen as the powerful occident that viciously preforms 
Enjy Noah Muhammad Hamouda

highly racist actions against the Arab Americans.

Therefore, the hostland expects neither negotiations nor exception to its policies. Expecting differences is hard to be dealt with in the hostland, which is clear in the American system of citizenship. In the American constitution, there are clear physical rejections to displaced communities (physical rejections is embodied in depriving immigrants in general and immigrants from Arab origins in specific of the social, political, judicial, educational, vote rights) and psychological hostility as Conner depicts "hostility towards the alien presence arose" (25). Although these displaced populations-who leave their homelands and hope for their new history in the new land as they are multigenerational- want to settle in and live in peace in the new state as their new home, they are perceived as outsiders in the eyes of the natives. As a result, there is some tension and pressure over diasporas of not being accepted and suffering from a constant feeling of alienation. Owing to perceiving the diasporas as outsiders, there is a constant conflict of belonging and not belonging. Tragically, racism turns to be so severe towards this new entity, diaspora, so Arab Americans start to feel psychologically displaced, exiled, and alienated from the hostland. 
Enjy Noah Muhammad Hamouda

This is depicted by the two Arab American poets: Adnan and Kahf who are exposed to all kinds of racism in America. In order to understand how displacement in terms of racism towards the Arab Americans in the hostland, this research paper employs the dramatic monologue as literary/ poetic technique in the analysis of the poetry of Adnan and Kahf. These two poets take advantage of dramatic monologue to reflect whatsoever conflicts the Arab Americans have been facing.

Although the dramatic monologue is the best poetic technique being known by Victorian poets, such as Robert Browning, Alfred Tennyson, and many others at the end of the nineteenth century, modern poets highly recommend re-exploring and reusing it. The use of the dramatic monologue technique in poetry is needful due to the politicizing nature of modern poetry. In other words there is a need to criticize political issues in an indirect way, such as using symbolism and dramatic monologue, through literature in general and poetry in specific. Dramatic monologue has been developed over ages as follows:

Dramatic monologue started as being titled dramatic lyrics then developed to be known as mental or psychological monologues. The 
Enjy Noah Muhammad Hamouda

dramatic monologue notion is discussed with the rise of reason and the superiority of mind in Europe; there is a huge tendency towards discovering the hidden dimensions of the human mind which explains much of the conscious mind. There are attempts to explore the objectives of dramatic monologue regarding the fact that it is being strongly used in literature. The dramatic monologue is exploited not simply to animate the past but also to interrogate history and the historical subject, to demonstrate that any attempt to reconstruct history will always be partial and interested. Questions of representation and interpretations consequently became central to the form" (Byron 5).

Hence, the dramatic monologue is used in literature as an effective tool to revisit the past and history in order to depict the fixed representations and interpretations. The dramatic monologue is the best technique to be used to reflect the internal conflicts and struggles of humans. Through this technique, the speaker 'I' fragments into a multiplicity of voices (Byron 6). Eventually, this research paper traces how Etel Adnan and Mohja Kahf employ the dramatic monologue in their poetry as a poetic technique in order to discuss displacement. 
Enjy Noah Muhammad Hamouda

There have been theories which try to codify the dramatic monologue as a genre. Therefore there are some theories that introduce the characteristics of dramatic monologue. There are seven characteristics that define and include dramatic monologue as mentioned as follows "The 'perfect' dramatic monologue is the one that would include seven characteristics: speaker, audience, occasion, revelation of character, interplay between speaker and audience, dramatic action, and action which takes place in the present" (Session 508). These seven items can be considered the reference to consider a dramatic monologue. First, these seven characteristics start with the speaker that later fragments into a multiplicity of voices, characters, and addresses the audience whether implicitly or explicitly. The readers are able to visualize the characters and be aware of the characters; gender, profession, and objectives. Regardless the multiplicity of the voices, these voices may not represent the poet at all. Sometimes the poet crosses gender in order to represent the burdens laid upon certain gender and provokes the readers' response. The poet may be a man, yet he speaks in the voice of a woman and vice versa. Sometimes the characters are involved in the conversation 
Enjy Noah Muhammad Hamouda

with the poet or left intentionally silent/passive "the silent auditor can be seen as a kind of poetic gadget which provokes us to break into our noisy response" (Maynard 74). Dialogism is a basic feature of dramatic monologue that is highly emphasized by critics. Next, since dramatic monologue focuses on revisiting the past/history, there are some certain actions referred to in the dramatic monologue. Then, there is an obvious identification of the speakers and the interaction between the speaker and the audience, whether positive response or passive one. Lastly, in order to use the dramatic monologue as a poetic technique in analysis, the poem should discuss current problematic issues that take place in the present.

Consequently, Kobena Mercer, one of the most influential diasporists, strongly suggests the possibility of finding dialogism in diasporic literature. Mercer states that "dialogic tendency which is responsive to the diverse and complex qualities of our differentiated specificity as a diaspora people. Dialogism occurs when incongruous voices press against one another inside a common arena" (56); in diasporic literature, he stresses the possibility of finding two different 
Enjy Noah Muhammad Hamouda

tones, whose interaction or contradiction is important to the text interpretation. Therefore, dialogism/dramatic monologue is used as a tool in diasporic literature in order to reflect the duality of the two places, cultures, traditions, languages, and religions clashing with each other in attempt to be united in one. With this in mind, this study shows how the two poets, Adnan and Kahf, use the dramatic monologue as a literary technique in depicting the Arab Americans' sufferings and conflicts. The research exposes the burdens represented by Adnan and Kahf through applying the dramatic monologue on their poetry. Dramatic monologue's main target is to question rather than to confirm any facts. Emphasis is on questions of representations, in order to demonstrate how cultural beliefs and fixed representations have been formalized. After displaying these negative fixed representations imposed on certain gender, race, or religion, dramatic monologue is used by Adnan and Kahf to deconstruct these negative representations which are imposed on the Arab Americans, due to difference in race and color.

First, Etel Adnan is an iconic Lebanese-American cultural figure Adnan; she combines in her poetry book, There, her experience 
Enjy Noah Muhammad Hamouda

of drawing with poetry. This research paper shows how Adnan gives us portraits/sketches that reflect whatever is related to the Arab Americans. Starting with the title, There: In the Light and the Darkness of the Self and the Other, Adnan uses 'there' as a symbol which will be used differently. There can be an idea or a place; it is used interchangeably throughout this collection to refer to many things at the same time.

Adnan divides her book of poetry, There, into thirty nine sections entitled "There”. In each section, Adnan uses 'there' differently, sometimes to refer to a place, other times to an idea. The first/opening section of "There" shows the fragmented self of the speaker due to discrimination. Without exposing the gender of the speaker, Adnan intends to hide the gender of the speaker to symbolize the whole race of Arab Americans. Here, Adnan introduces a speaker who is interrogating the American government. A speaker exclaims:

Where are we? Where? There is a where, because we are,

Stubbornly, and have been, and who are we, If not you and Me? 
Enjy Noah Muhammad Hamouda

Where is where, where the terror, the love, the pain? Where

The hatred? Where your life, and mine?

Who are we, a race, a tribe, a herd, a passing phenomenon. (Adnan 1)

From the very beginning, the speaker tries to define 'where' which refers to the hostland. The speaker addresses an imaginative audience (you $\&$ me). The speaker stresses the idea that "where is where, where the terror, love, pain and hatred" (Adnan 1). He/she refers to the hostland as a place, where is full of terror, love, pain, and hatred. The speaker is being objective by mentioning love that exists among other negative feelings, such as terror and hatred. Although there are a lot of hard feelings in the hostland, such as rejection, resentment, and rage against the Arab Americans, Adnan sheds light on the minor positive thing, love. Adnan wants to say we can work on and increase love in order to live together normally. From the very beginning the poet shows and laments the harsh rejection of the Arab Americans. She and the Arab Americans see themselves in a highly negative way "who are we, a race, a tribe, a herd, a passing phenomenon" (1). Adnan presents a shocking fact from the beginning of the poem, that the Arab Americans are not perceived as 
Enjy Noah Muhammad Hamouda

equal citizens. On the contrary, the poet is unable to define herself with a definite race. So, from the beginning, Adnan stresses both the highly negative perception of the Arab Americans and the harsh experience of racism the Arab Americans are facing.

Moreover, Adnan employs a speaker in an attempt to investigate the reasons behind these negative stereotyped representations of the Arab Americans. Here, the speaker imagines the American government as someone in order to address direct questions as follows:

Is there hatred in your heart, and does it mean that I am not Here, and where are you when it's getting late?

To go, be going, straight ahead, the world being round, to be

Coming back, to where, to what, to be a bouncing ball,

Where, on what, to be defeated by gravity.

Who are you when you're not me, and who am I?

Should we be intelligent enough to wipe ourselves off the face of the earth?

(Adnan 2) 
Enjy Noah Muhammad Hamouda

Through a dialogue between the speaker and the audience, the speaker addresses the American government. By using a metaphor, the speaker compares the heart as a box that is full of hatred which is something concrete. From here on, he/she continues on stressing the invisibility of the Arab Americans in the U.S. Due to that great amount of rejection and hatred, the speaker is highly desperate from the marginalization and racism that face the Arab Americans. The speaker states "the world being round", in which he/she compares the racist world/life in America with a circle, the Arab Americans cannot escape that vicious circle of being perceived as not quite white, backwards, and terrorists.

Due to displacement and marginality, Adnan wants to clarify this awful feeling of rejection. Walker Conner argues that "it is the hostility evident within the hostland that turns the guest into a segment of people living outside the homeland...Hostility towards the alien presence arose" (25). To illustrate this kind of hostility towards the Arab Americans, Adnan uses the speaker of the poem to ask the American government the reasons for these vicious stereotyping as follows: 
Enjy Noah Muhammad Hamouda

Are you keeping my door closed or are you coming at night with The key, the food, the smile, the hatred and the love?

Are you there in the dark?

Could they kill your old neighbor, (would they prevent him from watching The new, that fatal night, would his soul look at his body in a pool of his own blood?)

Yes they will, and you would do the same, the killing comes first, the reason, after.

It is always too late, too late for what? For the conversation we want to carry one late

Afternoon, but war is around us, visible at different degrees of sharpness. We always

Die on some well-defined spot. (Adnan 5 and 7)

By using of the adjective "hatred" the speaker expresses the Arab Americans astonishment of the amount of hatred towards them, the adjective "hatred" implies the strong and harsh impact of racism on the Arab Americans. He/she uses many symbols, such as night, dark, blood to show the evil side of stereotyping and to show how the Arab Americans 
Enjy Noah Muhammad Hamouda

are suffering in the hostland. The speaker refers to the power of media over directing the public perception of the Arab Americans. He/she concludes this section with his/her despair that it is late for conversation. Adnan highlights the Arab Americans' despair; she doesn't think talk would improve the image of the Arab Americans, especially after being negatively represented in the American media.

Secondly, Mohja Kahf is quite the same in her acknowledgement of dislocation, which comes as a result of not being accepted in the new home. She tackles how discrimination in the hostland against her race is severe. Kahf represents another generation of Arab Americans. Kahf's book of poetry, E-mails from Scheherazad (2003), shows us the updated action of racism against Arab Americans. Her book is divided into fifty poems in which she tackles non-related topics. She represents in brief how it feels to be an Arab American. It is emphasized by diasporists that hostile towards diasporas existed, such as Conner who argues that "the prejudice and bias against newcomers have often been great" (33). Kahf displays her experience of being rejected, despite the fact that she belongs to the modern generations of Arab Americans. 
Enjy Noah Muhammad Hamouda

Kahf's sense of dislocation comes from being racially stereotyped in America. She also employs different speakers in her poems. This is shown in her poem "The Skaff Mother Tells the Story", the speaker is a mother talking to her children as follows:

Have they found wool?

To keep them warm in their new land?

We sent them away, fourteen and fifteen is too young to suffer war. That's us small, weightless, voyager.

It's faded where it's been folded, because I carried it in a pocket called heart.

And where did I go? And what did I become? And in my new home did I eat

Cherries? And in my adopted family was I warm like Aleppan wool?

What happens to a child who can no longer speak the language of its mother.

(Kahf 14)

Parallel to Adnan's use of dramatic monologue, Kahf employs dramatic monologue as a main technique that helps her to give us a journey inside 
Enjy Noah Muhammad Hamouda

her thoughts. Kahf imagines a speaker, a mother who may be a symbol for Syria, talking to her children. The speaker tries to expose the feelings of the Arab American immigrants, who are cold, that is a symbol of racism and rejection. The speaker compares the Arab Americans as her kids who are cold, and are not being taken care of, but on the contrary they are being discriminated against, the speaker clarifies the characteristics of these children as young fourteen and fifteen' to show that racism hurt even the kids. It is not about age rather than race. Kahf wants to reflect how racism can affect the citizens' sense of self-worth. The poet ends this poem with her emphasis on the obligated feeling as being worthless due to race and color.

In addition, Kahf goes on giving us another side of racism against the Arab Americans. She introduces another speaker in her poem "The Passing There" as states:

My brother and I crossed through a field.

We were nine and ten.

The man owned the field was no Robert Frost 
Enjy Noah Muhammad Hamouda
Although he spoke colloquial "Git
Off my property" he shouted "or I'll..."
The rest of what he said I don't care

To repeat. It expressed his concerns

\begin{abstract}
About our religion and ethnic Origin
\end{abstract}
My brother knows this song: running home behind us,

A field that wasn't ours, ahead, a house of alien expectations (18)

Kahf chooses a speaker this time to be a child who is ten years old to discuss how the Arab American children are being victimized in the hostland. Here, the speaker uses the slang language is used by the Americans themselves in order to shed light to the offensive way of talking to the kids by the Americans, despite the fact that they do nothing except playing. Here, he/she gives a visual and auditory image of the experience of discrimination imposed on her race in America. Although the speaker here is a child, she shows how Arab Americans' children and grown-ups are being discriminated. The poet gives us a visual image of 
Enjy Noah Muhammad Hamouda

Arab American kids who are playing innocently, and then he/she shocks us with the harsh words that are being said to them by someone American. Kids are not excluded from discrimination due to their religion and race backgrounds. Here, Kahf rings a bell announcing the danger that is surrounding the Arab American kids.

\section{Conclusion}

In conclusion, displacement, which includes moving from one homeland to settle in another hostland, can be seen through highlighting racism imposed on the displaced populations. Displacement can be seen through racism against the Arab Americans that leads to the loss of belonging to the United States. The two poets try to expose how racism affects them to be truly suffering from the harsh experience of displacement as they do not feel being at home or secured. The Arab Americans cannot find belonging to the hostland. Racism in the hostland intensifies their dislocation. Both poets convey the Arab Americans struggle as being stereotyped and negatively perceived. With the exposure to racism, the Arab Americans crash with the American supreme discriminated perception against them; they are left dislocated. 
Enjy Noah Muhammad Hamouda

\section{Bibliography}

Adnan, Etel. There: In the Light and the Darkness of the Self and of the Other.

California: the Post-Apollp Press, 1997. Print.

Armstrong, John A. "Mobilized and Proletarian Diasporas." American Political

Science Review. University of Minnesota Press, 1976. Print.

Ashcroft, Bill, et al. Key Concepts In Post-Colonial Studies. New York: Routledge, 1998. Print.

---. The Empire Writes Back. London: Routledge, 1989. Print.

Boyarin, Jonathan and Daniel Boyarin. Powers of Diaspora: Two Essays on the Relevance of Jewish Culture, Minneapolis: University of Minnesota Press, 2002. Print.

.Byron, Glennis. Dramatic Monologue. London: Routledge, 2003. Print

Cohen, Robin. "Diaspora: Changing Meaning and Limits to the Concept". 6 May 2015. Web

---. Global Diaspora: An Introduction. London: University College London Press, 1997. Print.

Conner, Walker. “The Impact of Homlands Upon Diaspora”, in G. Sheffer, ed, Modern Diasporas in International Politics. London: Croom Helm, 1986. Print.

JanMohamed, Abdul R. "The Economy of Manichean Allegory: The Function of Racial Difference in Colonialist Literature." Critical Inquiry. Chicago: 
Enjy Noah Muhammad Hamouda

University of Chicago Press, 1985. Print.

Kahf, Mohja. E-mails from Scheherazad. Florida: University Press of Florida, 2003.

Print.

Loomba, Ania. Colonialism/Postcolonialism. London: Routledge, 1988. Print.

Maja, Lisa Suhair. “E-mails from Scheherazad”. Goodreads. 12 December 2016.

.Web

Majaj, Lisa Suhair, et al. Etel Adnan: Critical Essays on the Arab-American Writer and Artist. North Carolina: McFarland and Company, Inc., Publishers, 2002. Print.

Maynard, J. Critical Essays on Robert Browning. New York: G. K. Hall, 1992. Print. Mercer, Kobena. "Diaspora Culture and the Dialogic Imagination: The Aesthetics of Black Independent Film in Britain." Critical Perspectives on Black Independent Cinema. Cambridge: MIT Press, 1988. Print.

Miller, Michael Laurence. "Comparative Diaspora." Uass.Edu. n.d. Web. 10 May 2015.

Mishra, Sudesh. Diaspora Criticism. Edinburgh: Edinburgh University Press 1td, 2006. Print.

"Nostalgia". Cambridge Dictionary. Google. 3 January 2017. Web.

Russell, Lynette, editor. Boundary Writing: An Exploration of Race, Culture, and

Gender Binaries in Contemporary Australia. Honolulu: University of Hawaii Press.2006. Print. 
Enjy Noah Muhammad Hamouda

Safran, William, et al, eds. "Diasporas in Modern Societies: Myths of Homeland and Return”, Diaspora. London: Routledge, 1991. Print.

---. Transnational Migrations: The Indian Diaspora. London: Routledge, 2009. Print. Said, Edward. Orientalism. New York: RandomHouse, 1979. Print.

---. Transnational Migrations: The Indian Diaspora. London: Routledge, 2009. Print.

Sessions, Ina Beth. The Dramatic Monologue in American Literature. Washington, .D.C.: Georgetown University Publisher, 1947. Print Sheffer, Gabriel, ed. Modern Diasporas in International Politics. London: Croom Helm, 1986.Print.

Suleiman, Michael W. Arabs in America. Philadelphia: Temple University Press, 1999. Print. 
Displacement in the Poetry of Etel Adnan and Mohja Kahf

Enjy Noah Muhammad Hamouda 